\title{
APROXIMACIÓN A UNA PRIMERA VISIÓN CIENTÍFICA CHILENA SOBRE TIERRA DEL FUEGO, ISLAS AUSTRALES Y ANTÁRTICA, 1892-1906
}

\author{
MAURICIO JARA F." \& PABLO MANCILLA G."
}

\section{RESUMEN}

Concluido el proceso de Independencia, los diferentes gobiernos chilenos se preocuparon de estimular la búsqueda del conocimiento de los territorios y espacios marítimos nacionales, interés que se reforzó en el tiempo por el trabajo realizado sistemáticamente por hombres de ciencia y personal especializado de la Armada de Chile. La configuración de una primera visión científica chilena sobre Tierra del Fuego, Islas Australes y la Antártica, se comprueba mediante la aparición y edición de revistas y boletines científicos, libros, artículos de prensa y la publicación de conferencias, además de producirse un nutrido canje y/o intercambio de revistas con instituciones extranjeras, en el período 1892-1906. En este artículo se analiza desde una perspectiva histórica quienes fueron los primeros investigadores $e$ instituciones chilenas y el contexto en que les tocó participar de estas actividades y habrían sido el impulso inicial para el desarrollo de la política antártica chilena durante el siglo XX. Los materiales utilizados provienen de fuentes impresas, diarios y obras generales y especializadas existentes en bibliotecas y archivos del país y Argentina.

PALABRAS CLAVE: Tierra del Fuego, Islas Australes, Antártica, ciencia chilena, política antártica chilena.

\section{A FIRST APROACH TO CHILEAN SCIENTIFIC VISION OF TIERRA DEL FUEGO, AUSTRAL ISLANDS AND ANTARCTICA, 1892-1906}

\begin{abstract}
After the end of the independence process, different Chilean governments were concerned with the promotion for knowledge searching in the national territories and maritime areas, an interest that was reinforced over time by the systematic work carried out by science men and the Chilean navy personnel. The configuration of a first chilean scientific vision of Tierra del Fuego, the Austral Islands and Antarctica is demonstrated through the publication and edition of scientific journals and bulletins,

* Universidad de Playa Ancha. Fac. de Humanidades, Depto. Historia. Av. Playa Ancha 850, Valparaíso, Chile. mjara@upla.cl.

* Universidad Santo Tomás. Dirección de Formación General. Av. Limonares 190, Viña del Mar, Chile. pmancillag@ santotomas.cl.
\end{abstract}


books, press articles and the publication of conferences, as well as an extensive exchange of journals with foreign institutions during the period 1892-1906. In this article, this process is analyzed from a historical perspective, examining which were the first Chilean researchers and institutions, and the context in which they participated in these activities that gave the initial impulse to the Chilean Antarctic policy during the $\mathrm{XX}^{\text {th }}$ century. The materials used are provided by printed sources, diaries and general and specialized works available in Chilean and Argentinean archives.

KEY WORDS: Tierra del Fuego, Austral Islands, Antarctica, Chilean science, Chilean Antarctic policy.

\section{INTRODUCCIÓN}

Todo parece indicar que fue a fines del siglo XIX que las actividades científicas chilenas comenzaron a ocuparse de los espacios terrestres y marítimos australes. En parte por la presencia de hombres de ciencia que integraban las expediciones europeas con destino a la Antártica, el interés de las autoridades nacionales por esos territorios a causa del diferendo limítrofe con Argentina y por las recomendaciones de los gobernadores del Territorio de Magallanes. ${ }^{1}$

Fuera de las causas antes mencionadas y la situación general por la que atravesaba el país por esos años, sin lugar a dudas, el impulso vital para el despertar científico e institucional provino de un pequeño y activo grupo de particulares, incluyendo a franceses y alemanes avecindados y otros que iban de paso; ellos habrían permitido que dichas actividades científicas pudieran intensificarse o en algunas disciplinas iniciarse y lograr rápidas vinculaciones y posicionamientos internacionales. Las interrupciones involuntarias sufridas en el quehacer científico nacional con el estallido de la Guerra del Pacífico y de la Revolución Civil de 1891, habían producido retrasos que ahora requerían ser normalizados y proyectados para contribuir al progreso intelectual y material del país.

A partir de estos años se fue instalando y fortaleciendo la noción que la ciencia era un desafío necesario para el país y que entregaba más

1 Jara, M. (2012). Las 'Islas Australes' y los prolegómenos de la política antártica chilena, 1892-1896. Estudios Hemisféricos y Polares, 3 (4), pp. 269-286. Entre los gobernadores de Magallanes, sobresalen: Daniel Briceño y Manuel Señoret, Carlos Bories y Froilán González.

2 Nos referimos a oficios, memorándum y memorias dirigidas al Ministerio de Relaciones Exteriores y Colonización por beneficios que perjuicios y por lo mismo no era aconsejable sustraerse a este proceso civilizador, así como tampoco debían abandonarse el restablecimiento y perfeccionamiento del orden institucional y la reconstrucción de la tranquilidad política y social para revitalizar las actividades industriales y las de orden intelectuales y científicas.

En este espíritu la zona austral chilena comenzó a ser objeto de sustantivos y novedosos estudios sobre geología, hidrología y climatología, entre otros. De lo anterior hay menciones y en otros casos abundantes informaciones en los documentos existentes en los Archivos Nacional de Chile y del Ministerio de Relaciones Exteriores, provenientes de los gobernadores del Territorio de Magallanes entre 1892 y $1906^{2}$, y donde se advierte que las autoridades políticas en Santiago habrían estado permanentemente alertadas del estado y situación de la colonización e industrias en la zona austral chilena y particularmente en los alrededores de Punta Arenas, Tierra del Fuego y en el entorno de la isla de Navarino en dirección hacia el Cabo de Hornos. Esta situación ha sido reconocida por algunos historiadores nacionales de estas últimas décadas, quienes al estudiarlas ${ }^{3}$ las han integrado en sus trabajos e interpretaciones.

Para el período en estudio las investigaciones de académicos de la Universidad de Chile y los trabajos ejecutados por la Armada de Chile en observación y registro de los fenómenos

los gobernadores de Magallanes desde Daniel Briceño, Manuel Señoret, Carlos Bories y Alberto Fuentes.

3 Mateo Martinic Beros, Armando Braun Menéndez, Oscar Pinochet de la Barra, Sergio Vergara Quiroz, Jorge Berguño Barnes, Enrique Campos Menéndez, Consuelo León Wöppke, Sergio Lausic Glasinovic, entre otros. 
de la atmósfera, las mareas, configuración de las costas y en especial la utilización de instrumentos y metodologías para el trabajo hidrográfico, son las que más vinculación y reconocimiento de la comunidad científica internacional tanto estadounidense como europea obtuvieron; en este último caso, los oficiales de marina Roberto Maldonado, Luis Pomar, Baldomero Pacheco y Oscar Viel, habrían sido los más fieles representantes. Junto a la Oficina Hidrográfica de la Armada de Chile, también sobresalió la Oficina de Límites, dependiente del Ministerio de Relaciones Exteriores, el Observatorio Astronómico Nacional, la Sociedad Científica de Chile y, después de 1908, el Instituto Sismológico Nacional.

Esta primera fase del quehacer científico nacional se intensificó en el tiempo, convirtiéndose en un factor importante del desarrollo científico chileno de la primera mitad del siglo XX. Durante esta fase y en relación con los espacios australes chilenos, el aporte y entrega de datos de referencia sobre los cambios del estado del tiempo y la seguridad en la navegación se realizó a través de las denominadas 'colaboraciones científicas' chilenas a las expediciones que iban a la Antártica, siendo estas el más destacado aporte. Pero lo más relevante de todo esto fue la coincidencia y aceptación que a este tipo de trabajo científico le asignaron las autoridades políticas nacionales y el apoyo que dieron a la creación de instituciones destinadas a tutelar, aumentar y proteger las investigaciones y las publicaciones científicas que comenzaban a circular en el país. A la prestigiosa publicación de los Anales de la Universidad de Chile, se agregarán otras en el corto plazo.

Lo que estaba pasando por entonces en el país era ni más ni menos que corolario de lo que acontecía en las más importantes sociedades geográficas y científicas de Europa y Estados Unidos, en donde se estaba fortaleciendo el trabajo de la investigación científica y dentro de aquello se procuraba abarcar y conocer todas las regiones del orbe y revalorizar los espacios australes y el propio continente Antártico como áreas prioritarias para la exploración científica $y$ el conocimiento de sus potencialidades económicas.

A diferencia de lo que había ocurrido durante las primeras cinco décadas del siglo XIX, ahora el componente científico -cincuenta años después- ocupaba un lugar preponderante junto a la dimensión política y económica de los nuevos descubrimientos; a esta etapa del descubrimiento antártico y del Polo Sur los historiadores polares la han denominado La Época de la Aventura y la Investigación y Época Heroica ${ }^{4}$. Esto explicaría por tanto, que a la importancia científica y las características de las expediciones llevadas a cabo por estos años hacia el Polo Sur, los gobiernos hayan respaldado a las universidades, sociedades geográficas y científicas de Europa y Estados Unidos, tales como la Sociedad Científica de París, Royal Geographic Society, American Geographical Society, American Philosophical Society, Smithsonian Institute y de observatorios científicos ubicados en diferentes lugares del mundo.

Las expediciones que se organizaron para cumplir esos cometidos científicos estuvieron dotadas de los más avanzados medios mecánicos y tecnológicos para poder detectar y descubrir yacimientos minerales y aumentar la explotación y comercialización de los abundantes recursos marinos existentes en los mares circundantes a la Antártica. Entre las más notables y aportativas expediciones al conocimiento geográfico y su divulgación se cuentan, entre otras: el noruego, Karl Larsen; los británicos, Cartens Borchegrevinck y Robert F. Scott; el alemán, Erich Von Drygalski; el belga, Adrien de Gerlache; el sueco, Otto Nordenskjöld; el francés, Jean B. Charcot; y el escocés, William S. Bruce.

En este sentido, las informaciones solicitadas por las instituciones y sociedades científicas internacionales, que buscaban por esos años que les colaborarán con datos y estudios sobre aspectos hidrográficos y atmosféricos de esta parte de América del sur, fueron un importante estímulo y reconocimiento en la comunidad científica nacional que rápidamente siguió los modelos de las sociedades científicas de Europa y Estados Unidos. ${ }^{5}$ Esto último, permitió posicionar los estudios que hasta ese momento se realizaban por la Universidad de Chile, el Museo de Historia

4 Kirwan, L. P. (2001). Historia de las exploraciones polares. Barcelona: Luis de Caralt Editor, pp. 221-392. 
Natural y la Oficina Hidrográfica, en un nivel de amplia aceptación internacional; los trabajos realizados por los buques de la Armada consistentes en registrar observaciones científicas y que luego eran incorporadas a las cartografías levantadas por la misma institución naval, se cuentan entre los principales aportes chilenos para el conocimiento de los canales y costas de Tierra del Fuego e islas australes.

\section{PRIMER CONOCIMIENTO SUBANTÁRTICO Y ANTÁRTICO CHILENO, 1892-1899}

La Oficina Hidrográfica de la Armada de Chile (OHA) que recién se había creado en 1875 es la institución chilena que más participación tuvo durante el I Año Polar Internacional (1882-1883). Este evento científico internacional se organizó por sociedades científicas europeas para seguir avanzando en el conocimiento de las diferentes zonas geográficas del mundo. A pesar del poco tiempo de funcionamiento la OHA aportó con algunos datos para la seguridad en la navegación y de la geografía del Territorio de Magallanes, el Cabo de Hornos y las islas de Diego Ramírez. Se debe recordar que en el extremo meridional americano y chileno se levantó una estación científica francesa en bahía Orange a cargo del capitán Louis F. Martial en su buque la Romanche para observar desde ese lugar el tránsito del planeta Venus.

En lo práctico para esa oficina técnica naval aquel acontecimiento científico internacional, constituyó un estímulo a su propio quehacer profesional y un imperativo institucional para la formación de numerosas generaciones de oficiales especialistas en esas materias y que con el andar de los años obtuvo el reconocimiento de numerosas academias y asociaciones científicas

5 Romero, H. (1962). La universidad y la investigación científica. Anales de la Universidad de Chile, 125, pp. 15-29.

6 Martinic, M. (2002). Marinos a caballo. Exploraciones terrestres de la Armada de Chile en la Patagonia Austral y la Tierra del Fuego, 1877-1897. Valparaíso: Editorial Puntángeles.

7 Artículos publicados en el Anuario Hidrográfico de la Marina de Chile con datos del continente antártico entre 1886 y 1889 : a) De autores anónimos: Un Año en el Cabo de Hornos, por el Doctor Hyades, Estudios sobre una tempestad giratoria observada en el Cabo de Hornos, Fenómenos comprobables internacionales.

Pero por esa fecha no solamente la OHA estaba aportando al desarrollo de la investigación o en esa línea de trabajos, pues también lo estaba el Museo de Historia Natural de Santiago. Esta institución ya visualizaba en el ámbito de las ciencias naturales y sociales, la importancia que tenían los estudios interdisciplinarios y el valor de las colaboraciones científicas. ${ }^{6}$ De esta nueva valoración se logró poner término a la fijación de las coordenadas de las principales ciudades del país; incrementar la recolección de muestras vegetales, animales y minerales con sus correspondientes conocimientos y; lograr una mejor comprensión de la influencia meteorológica y oceanográfica que el continente antártico tenía sobre Chile. ${ }^{7}$ Estos resultados fueron integrados a las investigaciones de entonces y a las que posteriormente realizaron expediciones extranjeras en los mares y territorios australes americanos y antárticos.

También en el año 1891 se creó la Sociedad Científica de Chile gracias a la iniciativa de hombres de ciencia nacionales y extranjeros residentes en el país, especialmente franceses, quienes nada menos recibieron el patrocinio oficial de la Premio Nobel gala, Madame Marie Curie. La idea de estos nuevos asociados era ayudar a promover las ramas científicas, tanto teóricas como aplicadas y profundizar en los estudios de Chile y de la América Meridional. ${ }^{8}$ La pronta aparición de las Actes de la Société Scientifique du Chili, órgano difusor de esta Sociedad, potenció aún más las actividades interdisciplinarias y los contactos con eruditos europeos, puesto que los artículos publicados en las Actes, eran resultados o derivaciones de investigaciones efectuadas tanto en Chile como en el extranjero. ${ }^{9}$

En paralelo a este nuevo y prometedor

de la atracción de los hielos sobre las masas de aguas vecina, Determinación de las coordenadas geográficas de Punta Arenas por la Comisión Brasilera del Paso de Venus, Nuevo sistema de proyección de la esfera, Trabajos de la Comisión Científica Francesa del Cabo de Hornos en 18821883 y Algunos fenómenos físicos del gran océano austral; b) Con autor: Lephay, J. El clima de la Tierra del Fuego y de las inmediaciones del Cabo de Hornos, Durand-Gréville, E. Estudio sobre las cartas náuticas y Bertrand, A. Memoria sobre la región central de las tierras magallánicas.

8 Sociedad Científica de Chile. (1891). Reglement. Actes de la Société Scientifique du Chili, I, p. VII. 
panorama para la ciencia en Chile, la Cancillería chilena comenzó a alertarse por la explotación frecuente e indiscriminada de los recursos pesqueros en las costas nacionales por pabellones extranjeros ${ }^{10}$; la casi nula población en Tierra del Fuego e islas australes ${ }^{11} y$; las amenazas futuras que se pudieran producir a los territorios australes por la omisión en el Tratado de Límites con Argentina de 1881 de la zona antártica.

Lo anterior, con seguridad, influyó decisivamente en el Presidente Jorge Montt Álvarez, para que encomendara al académico de la Universidad de Chile y miembro de la Sociedad Científica de Chile, Rodolfo Philippi, a retomar lo realizado por la Comisión creada por el Canciller Luis Aldunate, en 1883, para estudiar el impacto que tenía la caza y pesca de lobos, nutrias y chungungos por estadounidenses y británicos en las costas y mares cercanos a Tierra del Fuego y al sur del Cabo de Hornos, actividades y capturas que estaban mermando notablemente las poblaciones y afectaban la economía de los empresarios puntarenenses. ${ }^{12}$ Lamentablemente esa primera comisión de 1883, y compuesta por Óscar Viel, Alfredo von Rodt y H. A. Honland, no logró avanzar en aquellos estudios a causa de una serie de complicaciones derivadas del lugar de residencia de cada uno de sus integrantes. ${ }^{13}$

La rápida actuación de Phillipi permitió tener al poco tiempo un estudio que derivó en la dictación de la Ordenanza de Pesca N 1.623 del Ministerio de Industrias y Obras Públicas, fechada el 17 de agosto de 1892; este nuevo cuerpo legal con el acuerdo del Consejo de Estado reglamentó la caza o pesca de focas o lobos marinos, nutrias y chungungos en las costas, islas y mares territoriales de Chile, significando con ello el inicio de la protección jurisdiccional y administrativa a las especies marinas existentes sobre las islas y aguas que se extienden desde Tierra del Fuego hacia el sur 'indefinidamente'. ${ }^{14} \mathrm{El}$ Territorio de Magallanes

9 Obrecht, A. (1891). Sur Les Mouvements du Sol à Santiago. Actes de la Société Scientifique du Chili, I, pp. 108114; Nogues, A. (1891). Quelques remarques sismiques, à propos de la communication de $\mathrm{M}$. Obrecht. Actes de la Société Scientifique du Chili, I, pp. 115-119.

10 Albert, F. (1901a). Los lobos marinos de Chile. Revista Chilena de Historia Natural, V, p. 41.

11 Paravic, S. (1988). Chile y el desafío antártico internacional. junto al archipiélago Juan Fernández eran para el gobierno las áreas geográficas prioritarias a las que estaba destinada esta ordenanza.

Parte del estudio de Philippi fue publicado en los Anales del Museo de Historia Natural en 1892, bajo el título Las Focas Chilenas del Museo Nacional, trabajo de gran valor para la historia antártica, pues aporta importantísimos datos sobre la extensión del territorio chileno, al señalar que las especies de lobo fino y de dos pelos: ya se habian extinguido por completo en todo el litoral del país, desde las regiones antárticas hasta el extremo norte [...] mientras que algunos [...] confirman su existencia en algunas islas antárticas de propiedad nacional. Agregando a continuación que, no obstante, no he tenido ocasión de observarla en los lugares antes nombrados, pero puedo asegurar que no existe en el país ni en la región comprendida entre Chiloé y la provincia de Atacama, como tampoco en las islas vecinas a la costa, el archipiélago de Juan Fernández, San Félix, San Ambrosio y la isla de Pascua, por lo tanto, debemos dejar a las expediciones futuras comprobar efectivamente si aún existen individuos vivos [lobos] en las regiones antárticas del país ${ }^{15}$.

A las instituciones antes nombradas es importante consignar que los trabajos científicos desarrollados por las expediciones de Nordenskjöld, Gerlache y Charcot, fueron conocidos en el Museo de Historia Natural de Valparaíso gracias al sistema de canjes e intercambios de publicaciones científicas, las cuales favorecieron la circulación de las mismas en los principales centros intelectuales y académicos del país.

En abril de 1895 el gobierno de Suecia dirigió al de Chile una nota en donde informaba que enviaría al geólogo Otto Nordenskjöld, acompañado de un botánico y un zoólogo, a cargo de una expedición financiada por la Universidad de Upsala, el Museo Nacional de Suecia, la Sociedad

Memorial del Ejército de Chile, 428, p. 101.

12 Las pesquerías de lobos en los mares magallánicos. (1894, 2 septiembre). El Magallanes de Punta Arenas, p. 2.

13 Albert, F. (1901b). Los pinípedos de Chile. Actes de la Société Scientifique du Chili, XI, pp. 219-257.

14 Romero, P. (1985). Presencia de Chile en la Antártica. Memorial del Ejército de Chile, 49, p. 112.

15 Albert 1901b, op. cit. pp. 219-257. 
Geográfica de Estocolmo y el barón Óscar Dickson, con el objeto de recorrer el Archipiélago de Tierra del Fuego y, tan luego como sea posible, avanzar sobre el continente antártico [...] dado que la finalidad era hallar, mediante estudios comparativos de las regiones nord y sud polares [...] explicación satisfactoria a diversos problemas científicos ${ }^{16}$.

En aquella nota, el gobierno sueco también reconocía explícitamente que por la cercanía geográfica de Chile, éste era el país que podía prestar algunos servicios y le solicitaba apoyar a la expedición con: el uso de escampavías de la Armada de Chile; el otorgamiento de licencias para pescar; la asistencia para adquirir víveres y contratar cargadores; permisos para atravesar las fronteras con liberaciones aduaneras sobre los equipajes $y$; en general, para concederles a los miembros de la expedición amplias protecciones y auxilios.

El presidente Jorge Montt Álvarez, acogió con beneplácito la solicitud sueca y le pidió al Gobernador de Magallanes, Manuel Señoret y a la naciente Sociedad Científica de Chile, colaborar y asistir a los expedicionarios europeos con toda clase de ayudas y datos científicos para el mejor éxito de sus investigaciones. ${ }^{17}$ Era la segunda vez que el gobierno chileno participaba de este tipo de colaboraciones científicas internacionales sobre la región austral americana y chilena, y en su proyección con la Antártica.

La estadía de Nordenskjold en el país, se extendió desde fines de 1895 y 1897, durante ese período se realizaron innumerables trabajos de exploración en las costas y territorios interiores de las regiones centrales y australes de Chile, utilizando como medio de transporte la escampavía Cóndor, que había sido puesta a

16 Escudero, J. (1953). Cincuentenario de la política antártica chilena. Boletín de la Academia Chilena de la Historia, XX (48), p. 73

17 Escudero 1953, op. cit. p. 73.

18 Berguño, J. (1998). El despertar de la conciencia antártica (1874-1914): Origen y desarrollo de la cooperación científica internacional. Boletín Antártico Chileno, 17 (2), p. 18; Barrera, H. (1983). Los asuntos antárticos y la participación de algunas instituciones chilenas. Boletín Antártico Chileno, 2, p. 18; Martinic, M. (1972). Nuevos antecedentes sobre actividades nacionales en el territorio antártico durante las primeras su disposición por el Gobernador del Territorio de Magallanes, Manuel Señoret. Esto le permitió a Nordenskjold recabar muchas informaciones y observaciones científicas que luego tuvo la oportunidad de compartir en Punta Arenas, Valparaíso y Santiago con miembros de la Sociedad Científica de Chile y, especialmente, con su Presidente, en ese entonces, también Ministro de Justicia e Instrucción Pública, Federico Puga Borne. De esta relación surgió el proyecto de planificar un viaje a las islas Shetland del Sur, en el verano de 1896-1897, en un buque de la Armada de Chile, probablemente la corbeta Magallanes que, a pesar de su mal estado, era utilizada para trabajos hidrográficos en el Estrecho de Magallanes y en Tierra del Fuego. ${ }^{18}$ Aunque el proyecto de expedición en la corbeta Magallanes no encontró acogida, en Argentina este hecho no pasó desapercibido y rápidamente se empezó a organizar el envío de una nave a las islas Shetland del Sur, la cual al poco tiempo después tampoco pudo materializarse. ${ }^{19}$

Pero la idea de una expedición sueca a la Antártica en una nave chilena obtuvo otro importante adepto dentro de la Sociedad Científica de Chile, la del botánico Francisco Fonck Foveaux ${ }^{20}$, quien llamó a la Armada de Chile, a través del artículo Bibliografía Maritima Chilena, publicado en la Revista de Marina en junio de 1896, a que siguiendo lo que otras instituciones navales del mundo hacían en tiempos de paz también pudiera apoyar y ocuparse de las ciencias hidrográficas y geográficas en zonas poco conocidas o aún desconocidas del Chile austral.

Para Fonck dicha propuesta se fundamentaba en lo avanzado de las exploraciones en las costas de la Patagonia, Estrecho de

décadas del siglo XX. Anales del Instituto de la Patagonia, III (1-2); Comisión Científica Sueca (1896, 26 enero), El Magallanes de Punta Arenas, pp. 2 y 3.

19 Las islas Shetland del Sud. Expedición argentina al polo austral - Mapa del archipiélago. (1896, 16 noviembre). La Prensa de Buenos Aires, p. 5.

20 Macaya, J. y Fonck, A. (2005). Francisco Adolfo Fonck Foveaux (1830-1912) y su importancia en la botánica chilena del siglo XIX-XX. Revista Chilena de Flora y Vegetación, 8 (2); Fonck, F. (1893). Introducción a la Orografía y Geología de la región austral de SudAmérica. Valparaíso: Ed. Carlos. 
Magallanes y Tierra del Fuego, y en la necesidad de integrarse a los trabajos científicos de los países europeos que estaban programando expediciones antárticas con el objetivo de contribuir a la ciencia; pero la principal razón por la cual Chile debía participar era porque se trataba del vecino más inmediato del polo antártico y dueño de aquella parte de la gran masa continental del globo que se extiende, en forma de punta, más adentro del mar austral que otra tierra alguna y en dirección al polo [...] además por flamear su bandera en el Cabo de Hornos a distancia relativamente corta de las primeras tierras antárticas [...] y, porque [...] si la posesión de esos desiertos valiera algo para el hombre, su propiedad correspondería en primer lugar a Chile ${ }^{21}$.

No obstante, para Fonck esos estudios debían fundamentarse en un plan de trabajos científicos preliminares.

En el mismo año de 1896, la Armada de Chile, a través del Anuario Hidrográfico, se mostró interesada por enviar uno de sus buques en comisión de exploración al continente antártico, especialmente, por las numerosas comunicaciones recibidas en la OHA de buques balleneros y mercantes que durante 1895 al navegar por las aguas australes, habían observado témpanos de grandes dimensiones en las cercanías del Cabo de Hornos provenientes de latitudes mayores. Estas noticias, habrían servido para potenciar los estudios en la OHA, pero una vez desechada la iniciativa de una expedición a la Antártica, por la falta de recursos y de una nave apropiada, se decidió entre sus prioridades realizar una mayor vigilancia en Tierra del Fuego e islas y mares que se extienden hacia el sur con el objeto de resguardarlos y observar el comportamiento

21 Fonck, F. (1896). Bibliografía Marítima Chilena. Revista de Marina, 121, pp. 130-131.

22 Oficina Hidrográfica de la Marina de Chile. (1896). Anuario Hidrográfico de la Marina de Chile, XIX, p. 111; Pacheco, B. (1930). Derrotero del archipiélago de la Tierra del Fuego. Anuario Hidrográfico de la Marina de Chile, XXXV, pp. 35-36.

23 Berguño, J. (1997). La exploración de los mares australes por navíos españoles durante el siglo XVIII. Boletín Antártico Chileno, 16 (2), p. 8; Becerra, R. (1895). Reglamento para llevar los diarios de bitácora. Revista de Marina, 113, pp. 545-551; Mouchez, E. A. B. (1897). de los hielos que transitaban a la deriva y poder prevenir a los navegantes de los peligros a los cuales se exponían ${ }^{22}$; no obstante, esta idea no era nueva en el mundo científico internacional, ya que muchas de las observaciones realizadas por navegantes durante el siglo XIX, terminaban por afirmar que el hielo marino era una barrera natural, pero también una de las llaves de acceso al continente antártico. ${ }^{23}$

Nordenskjöld, apenas terminó sus trabajos en la Patagonia y Tierra del Fuego, en mayo de 1897, volvió a su país. Antes de partir de Santiago se comprometió a enviar los resultados de sus investigaciones a la Sociedad Científica de Chile. ${ }^{24}$ Posteriormente, en noviembre del mismo año, escribió a la Sociedad agradeciendo la ayuda prestada y adjuntando algunos folletos científicos sobre las exploraciones realizadas ${ }^{25}$; uno de estos trabajos fue publicado en las Actes de la Société Scientifique du Chili bajo el título de Algunos Datos sobre la Parte Austral del Continente Sudamericano, según Estudios Hechos por la Comisión Científica de Suecia ${ }^{26}$. En este estudio Nordenskjold señalaba: que al planificar la comisión para estudiar bajo todos los puntos de vista posibles la parte del mundo accesible más avanzada hacia la región desconocida del continente antártico, es decir, la Tierra del Fuego y sus territorios adyacentes, me he dado cuenta de que a pesar de que han sido visitadas por tantas expediciones que han traido de ellas grandes colecciones zoológicas y botánicas, aún se puede decir que la generalidad de su geografía física es muy poco conocida. Luego de este primer comentario general sobre Tierra del Fuego, el geólogo sueco sostenía que: es muy curioso notar que en un territorio tan interesante $y$

Hidrografía y levantamientos rápidos durante los viajes. Revista de Marina, 133, pp. 17-34.

24 Sociedad Científica de Chile. (1897). Sesión General en 5 de julio de 1897. Actes de la Société Scientifique du Chili, VII, p. XXX.

25 Sociedad Científica de Chile. (1897). Sesión General en 15 de noviembre de 1897. Actes de la Société Scientifique du Chili, VII, p. XXXVIII.

26 Nordenskjöld, O. (1897). Algunos datos sobre la parte austral del continente sudamericano según estudios hechos por la comisión científica Suecia. Actes de la Société Scientifique du Chili, VII, pp. 157-168. 
variado no se hayan hecho estudios detallados, comparando tanto las distintas regiones entre sí, con otras de Sudamérica y del hemisferio norte, como también los resultados de varias exploraciones para obtener una idea exacta sobre la topografía del territorio, menos sobre la naturaleza de aquella y las causas que la produjeron o siquiera sobre las variaciones más importantes que experimentó en las épocas geológicas. Al concluir su estudio recomendaba que sería de suma importancia para la historia natural general el estudio de los vestigios de una época no muy remota, fría, glacial, que creyeron encontrar varios viajeros, pero cuya existencia en el continente sudamericano han negado otros por completo, como asimismo, muchos otros son los problemas que aqui deben encontrar su solución, como por ejemplo, las causas de la existencia, en los mares y tierras australes, de muchas especies de animales $y$ plantas que viven también en el norte, pero que no se encuentran en todo el inmenso territorio intermedio ${ }^{27}$.

Otro de los temas estudiados por Nordenskjold en Tierra del Fuego y que causó mucha atención y preocupación de los empresarios y de las propias autoridades del Territorio de Magallanes fueron los depósitos de Carbón de Piedra, recientemente descubiertos en Tierra del Fuego pues son de una calidad muy superior a la del carbón lignítico que se encuentra en las minas del Río de las Minas cerca de Punta Arenas ${ }^{28}$.

Nordenskjöld publicó los resultados finales de su viaje en la obra Fran Eldslandet ${ }^{29}$. En ésta expresaba su profunda gratitud por la espléndida hospitalidad recibida durante su estadía en Chile. Agradecía al gobierno de Chile por el interés mostrado por sus investigaciones, a la Armada, a

27 Nordenskjöld 1897, op. cit. pp. 157-168.

28 Carbón de Tierra del Fuego. Informe del Dr. N. Otto G. Nordenskjold sobre su visita a las minas de carbón cerca del río Cóndor, Tierra del Fuego. (1896, 3 mayo). El Magallanes de Punta Arenas, p. 3.

29 Gajardo, I. (1903). Un socorro oportuno a los expedicionarios del Antarctic. Revista de Marina, 204, p. 703; Beauvor, J. M. (1915). Los Shelknam: Indigenas de Tierra del Fuego. Buenos Aires: Talleres Litográficos de la Compañía de Fósforos, p. 215.

30 Escudero 1953, op. cit. p. 74. los hombres de ciencia y a los medios de prensa chilenos, así como también a los comerciantes y agricultores de Magallanes, en forma especial al Gobernador Manuel Señoret por todos los apoyos y colaboraciones brindadas e igualmente, y en no menor consideración, por todos los sacrificios realizados para el éxito de nuestros estudios en Tierra del Fuego y mares australes. ${ }^{30}$ Nordenskjold se fue satisfecho de lo realizado y muy esperanzado de volver en otra oportunidad para poder ir a latitudes mayores: a la Antártica.

A los pocos meses que Otto Nordenskjold había regresado a Upsala, llegó a Punta Arenas, en diciembre de 1897, el teniente de navío belga Adrien de Gerlache en su nave Bélgica con el objeto de reaprovisionarse y hacer un breve descanso antes de emprender viaje hacia Tierra del Fuego a estudiar a los indígenas ${ }^{31}$ y luego emprender rumbo hacia el continente antártico para efectuar investigaciones sobre magnetismo y geografía física de esa enigmática región del orbe que en el último congreso de geografía de Berlín de 1896 había sido definida como un área prioritaria para el quehacer científico.

Desde la perspectiva del Territorio de Magallanes, la expedición antártica belga fue una inesperada oportunidad para advertir que la cercanía con el continente antártico era algo que había que saber aprovechar y proyectar en el futuro; era la primera vez que se estaba frente al significado $y$ valor que ese inmenso y desconocido espacio austral que era la Antártica representaba para el Territorio. ${ }^{32}$

Durante la visita del Bélgica en Punta Arenas sus oficiales y tripulantes tuvieron contactos con la sociedad y autoridades e incluso uno de los científicos de la expedición se comprometió con la OHA a remitir todos los antecedentes e informaciones científicas sobre

31 Berguño, J y Canales, R. (2005). La Antártica en Punta Arenas, ayer y hoy. Boletín Antártico Chileno, 24 (2), p. 21; Vercel, R. (1942). Al Asalto de los Polos. Santiago: Ed. Difusión, p. 156; Donoso, Á. (1906). Demarcación de la línea de frontera en la parte sur del territorio: Trabajos de la Quinta Sub-Comisión Chilena de Límites con la República de Argentina. Santiago: Imp. Cervantes, p. XXXIV.

32 Jara, M. (2013). Gerlache's Belgique in the social imaginary of Punta Arenas, 1897-1899. Estudios Hemisféricos y Polares, 4 (3), pp. 200-210. 
los nuevos descubrimientos para que fueran publicados en el Anuario Hidrográfico. ${ }^{33}$

Pero no sólo el órgano oficial de la OHA recibió algunos resultados del viaje de Gerlache pues también fueron incluidos en la Revista Chilena de Historia Natural del Museo de Historia Natural de Valparaíso a través de los siguientes títulos: Los Musgos Colectados por la Expedición Antártica Belga en el Estrecho de Magallanes y Tierra del Fuego (1900) y Dípteros Nuevos Chilenos Descubiertos por la Expedición Antártica Belga (1903) ambos de Carlos Porter ${ }^{34}$ y, Carábidos Nuevos Chilenos Descubiertos por la Expedición Antártica Belga de Federico Delfín. ${ }^{35}$

El que la Revista Chilena de Historia Natural de Valparaíso fuera un medio de difusión de los trabajos de Gerlache no tuvo nada de extraño por cuanto durante los primeros años del siglo XX esta revista formó parte de una red nacional $e$ internacional de canje de publicaciones y en ese sentido contribuyó con diversos datos sobre las zonas subantárticas y antárticas, ampliando los conocimientos de su geografía, zoología y botánica, y de las amplias posibilidades económicas y científicas que esos territorios ofrecían al futuro desarrollo nacional.

\section{LO SUBANTÁRTICO Y ANTÁRTICO EN LA DIMENSIÓN INTERNACIONAL Y NACIONAL, 1899-1906}

La convergencia de los hechos nombrados, permitió la formación de un nuevo escenario para el conocimiento y difusión de los espacios australes chilenos, el cual estuvo caracterizado por una renovación del interés científico nacional, una mayor importancia de Punta Arenas como centro de operaciones para las expediciones científicas antárticas y un mayor número de hombres de

33 Oficina Hidrográfica de la Marina de Chile. (1901). Anuario Hidrográfico de la Marina de Chile, XXIII, p. 10.

34 Porter, C. (1900). Los musgos colectados por la expedición antártica belga en el Estrecho de Magallanes y Tierra del Fuego. Revista Chilena de Historia Natural, IV, pp. 102-106; Porter, C. (1903). Dípteros nuevos chilenos descubiertos por la expedición antártica belga. Revista Chilena de Historia Natural, VII, pp. 218-220.

35 Delfín, F. (1903). Carábidos nuevos chilenos descubiertos por la expedición antártica belga. Revista Chilena de Historia Natural, VII, p. 229. ciencia para iniciar los estudios en dichas zonas. ${ }^{36}$ También durante estos ocho años el país conoció y participó de una serie de acontecimientos directamente relacionados con el continente antártico y del cual no se desvinculará más.

Sin embargo, para el gobierno chileno todavía seguía subsistiendo el problema de la explotación de los recursos marinos; el peligro de posibles reclamaciones de soberanía de otros países y; la falta de unidades navales y elementos técnicos y operativos apropiados para poder llevar adelante las labores de resguardo de estos recursos. Esto habría influido en Federico Chaigneau para que a través del artículo titulado La Pesca ante el Porvenir de la Marina de Guerra, publicado en la Revista de Marina en diciembre de 1898, éste oficial naval hiciera un llamado al gobierno de Federico Errázuriz Echaurren, para incentivar las actividades industriales y el comercio marítimo nacional. Del mismo modo, pudiera el gobierno iniciar un programa de dictación de leyes prudentes y protectoras para conservar las especies marítimas y para lo cual se debería traspasar la dirección del ramo de pesquería existente en el Ministerio de Industria y Obras Públicas al Ministerio de Marina. Según Chaigneau, esto último, permitiría que la Armada de Chile, forzosamente, se convirtiera en promotora de las investigaciones científicas, especialmente, oceanográficas y definir la existencia de posibles bancos para la exploración pesquera, lo que proporcionaría una provechosa ocupación de los buques en tiempos de paz y contribuiría a la defensa y prosperidad de Chile en las aguas al sur del Estrecho de Magallanes y Tierra del Fuego. ${ }^{37}$

A raíz de la decisión adoptada en el sexto Congreso de Geografía de Berlín en 1896 respecto de organizar y coordinar el envío de cinco expediciones al Polo Sur ${ }^{38}$, el gobierno chileno fue requerido por la cercanía con las aguas y

36 Toro, C. (1986). Presencia de Chile en la Antártica. Santiago: Ed. Universitaria, p. 22.

37 Chaigneau, F. (1898). La pesca ante el porvenir de la Marina de Guerra. Revista de Marina, 150, pp. 2194-2196; Ministerio de Marina. (1896). Memoria del Ministerio de Marina. Santiago: Talleres Tipográficos de la Armada, pp. 227-230.

38 Del británico Robert Falcon Scott; del alemán Erich von Drygalski; la sueca de Otto Nordenskjöld; la escocesa de William S. Bruce. Posteriormente, se organizó la francesa Jean Charcot. 
tierras antárticas para que cooperase con dichas expediciones. El Presidente Federico Errázuriz Echaurren en 1899 solicitó al Observatorio Astronómico, dirigido por el académico de la Universidad de Chile y miembro de la Sociedad Científica, Alberto Obrecht y a la OHA, colaborar con la entrega de datos meteorológicos y magnéticos a las misiones antárticas del alemán Erich von Drygalsky y con la del ya conocido geólogo sueco Otto Nordenskjöld ${ }^{39}$, quien ahora vendría con nave propia y tendría por destino la Antártica.

En octubre de 1901 el gobierno sueco solicitó a través de su Cónsul en Valparaíso al Presidente Germán Riesco Errázuriz, prestar ayuda a Nordenskjold en su viaje a la Antártica, considerando que: esta expedición será igualmente de interés para el gobierno de Chile, pues recogerá datos y experiencias respecto de la pesca de ballenas y de focas en aquellas regiones remotas $^{40}$.

El viaje de Nordenskjöld al continente antártico, se inició en Europa a mediados de 1901 y a pesar de la ayuda requerida a La Moneda, la ruta de navegación planificada por el geólogo sueco no contempló arribar a puerto chileno. No obstante, en marzo de 1902, al regresar la nave Antarctic de su primera campaña por esos mares y dejar en la isla Snow Hill a Nordenskjold junto a otros cinco de sus compañeros, y donde estaba el marino argentino José María Sobral, la escampavía Huemul de la Armada de Chile, comandada por el teniente Ismael Gajardo Reyes, y que se encontraba fondeada en la bahía de Ushuaia tuvo un contacto casual con los oficiales de esa nave de la expedición sueca.

Dicho encuentro, que duró tres días, fue de significativo interés para el comandante y los oficiales de la escampavía chilena, quienes tuvieron la oportunidad de conocer las experiencias adquiridas por los tripulantes del Antarctic, las

39 Berguño 1998, op. cit. p. 9; Escudero 1953, op. cit. p. 75.

40 Escudero 1953, op. cit. p. 75.

41 Gajardo, I. (1905a). Por los mares australes: Reminiscencias de la primera campaña del Antarctic a las Tierras del Rey Óscar II. Revista de Marina, 228, pp. 641-644; Gajardo, I. (1905b). Viaje de la escampavía Huemul a las islas australes de la Tierra del Fuego en marzo de 1902. Anuario Hidrográfico de la Marina de instalaciones de la nave y las cartas de navegación que utilizaban en esas apartadas regiones. ${ }^{41}$

Casi paralelo al encuentro del teniente Gajardo con los tripulantes del Antarctic en Ushuaia, el gobierno del Presidente Riesco, otorgó en 1901 y por primera vez un arrendamiento de tierras y sus proyecciones marítimas al sur de Tierra del Fuego ${ }^{42}$; esta concesión recayó en la persona de Ruperto Vives Solar y todo hace pensar que habría sido para contrarrestar la imposibilidad que tenían las autoridades marítimas de Magallanes para fiscalizar la pesca y la caza clandestina, cada vez más abundante, y que las disposiciones de la Ordenanza de 1892 no otorgaban un marco regulador para el establecimiento de industrias. Un año después, a fines de diciembre de 1902, el Presidente Riesco nuevamente hará uso de este recurso de concesión a un particular, beneficiando a un vecino de Punta Arenas.

Esta última concesión, tuvo entre sus disposiciones, la obligación de realizar observaciones meteorológicas, zoológicas y botánicas, que serían reguladas por la Sección de Ensayos Zoológicos y Botánicos del Ministerio de Industrias, dirigida por el botánico alemán Federico Albert Faupp, quien en ese momento cumplía funciones académicas en el Instituto Pedagógico, de investigación en el Museo de Historia Natural y que también planificaba y ejecutaba exploraciones a distintas zonas del país para conocer y preservar los recursos naturales. ${ }^{43}$

Ese mismo año de 1902 regresó al país el Adicto Naval de la Legación de Chile en Estados Unidos, Luis Pomar Ávalos, para asumir por segunda vez el cargo de Director de la OHA. Pomar, hidrógrafo de alta especialización y amplios contactos a nivel mundial, durante su gestión participó como delegado nacional en la Exposición de Buffalo de 1904, donde expuso sobre los trabajos y nivel de las investigaciones geográficas de la OHA; además, y con la aprobación de la Dirección General de la Armada, logró restringir

Chile, XXV, pp. 30-43.

42 Ministerio de Marina. (1903). Memoria del Ministerio de Marina. Santiago: Talleres Tipográficos de la Armada, pp. 489-495.

43 Romero 1985, op. cit. pp. 40-41; Escudero 1953, op. cit. pp. 77-78; Destefani, L. (1982). Malvinas, Georgias y Sándwich del Sur ante el Conflicto con Gran Bretaña. Buenos Aires: Ed. Edipress, pp. 97-98 y 101. 
el campo de acción de la OHA que, según él: ya había cumplido su ciclo de centro científico de carácter general, lugar que había mantenido desde sus primeros años cuando no existían las numerosas y diversas instituciones especiales con que ahora contaba el país, donde fue al mismo tiempo geográfica, topográfica, meteorológica, etc., prestando a todas las diversas ramas de la ciencia, que entonces estaban en ciernes en el país, positivos servicios, muy conocidos $y$ altamente apreciados, tanto dentro como fuera del pais ${ }^{44}$.

Con Pomar la OHA en 1903 comenzó a priorizar los trabajos en los océanos Pacífico y Atlántico austral, con el objeto de servir a la navegación de las naves de la Armada de Chile $y$ de las marinas mercantes que frecuentaban estas costas y mares ${ }^{45}$; además, de incentivar la apertura de otras ramas de la ciencia que hasta ese momento estaban poco atendidas en el país, como la hidrografía, meteorología, climatología y oceanografía, pero que a nivel mundial estaban siendo de gran interés para impulsar las industrias pesqueras y de transporte marítimo en el mundo. No obstante, se debe reconocer que la OHA hacia esa fecha ya había hecho varias tentativas sin mucho éxito para colaborar en las labores científicas internacionales y contribuir a ampliar este tipo de estudios en el océano Pacífico y que por entonces eran estudiadas en profundidad por instituciones científicas de otros países, como el Weather Bureau de Washington y el Instituto Smithsoniano.

Como estos estudios, según Pomar Ávalos, se habían hecho aún más extensos, la OHA debía ampliar su campo de investigación hasta el mismo continente antártico, con el objetivo de ser un valioso apoyo a los intereses de la industria lobera y ballenera, que con el acelerado agotamiento de estos recursos había tenido que buscar nuevos centros para la caza y la pesca en las islas Shetland del Sur, islas que eran constantemente frecuentadas por buques chilenos, argentinos, estadounidenses, británicos, entre otros.

También, por otra parte, con el aumento

44 Oficina Hidrográfica de la Marina de Chile. (1903). Anuario Hidrográfico de la Marina de Chile, XXIV, p. 9.

45 Ministerio de Marina 1903, op. cit. pp. 399-412. de la navegación nacional en aquellos mares de la Antártica, permitió a la OHA con los años, dedicar más atención y estudiar la formación y desplazamiento de los hielos antárticos y sus posibles influencias en la climatología del país.

Respecto de lo anterior, el mismo director de la OHA, Pomar, basándose en sólidos conocimientos disciplinarios y en un evidente grado de especialización, sostenía en 1903 que la baja latitud de los icefields antárticos durante el verano es signo precursor, al revés de lo que podría creerse de un invierno menos frío y menos lluviosa que los normales. Naturalmente no bastan los pocos casos observados para plantear un sistema ni se puede hacer deducciones seguras. Inútil es insistir en la considerable importancia que tendrían estos pronósticos a largo plazo el día que pudieran asentarse sobre base segura, y cuantos millones se ahorraría a la primera de nuestras industrias nacionales cuando se le pudiera avisar el tiempo que reinará en la estación en que se inician los cultivos o se eligen los que ofrecen mayores probabilidades de éxito. Llamará la atención esta cooperación de la Marina a la agricultura, posible únicamente en nuestro país, en atención a su configuración geográfica, que lo hacen un país exclusivamente marítimo hasta la misma cresta de la cordillera, y a la corriente polar que baña toda su costa y que modifica profundamente su clima. Una reflexión más nos merece este punto de climatología, y es la frecuencia con que se observa primaveras lluviosas o muy húmedas en el norte del país, hasta la frontera peruana, cuando ha ocurrido un invierno de los llamados benignos en la región central. Si estas coincidencias fueran frecuentes, y resultaran bien relacionadas, sería probable que su causa fuera la misma ya indicada, y tendríamos que ir a buscar la razón de nuestros cambios climatológicos anuales en las variaciones periódicas de la extensión y contorno del gran casquete de hielo que circunda el polo vecino ${ }^{46}$.

Mientras la OHA se encontraba ajustando sus actividades profesionales para poder ampliar

46 Oficina Hidrográfica de la Marina de Chile 1903, op. cit. pp, $10-11$ 
sus campos de investigación hasta el continente antártico, los medios de prensa europeos, trasandinos y nacionales comenzaban a informar sobre el desconocimiento que se tenía de la expedición de Nordenskjöld en el sexto continente; la Antarctic era esperada en Ushuaia para los meses de abril-mayo de 1903, y por tal motivo los gobiernos de Argentina y Suecia estaban planificando el envío de una expedición de rescate. ${ }^{47}$

En el contexto de este rescate, el teniente Ismael Gajardo, quien había tenido contacto con el Antarctic un año antes, propuso en un artículo de junio de 1903, titulado Un Socorro Oportuno a los Expedicionarios del Antarctic y publicado en la Revista de Marina, que el gobierno chileno debía adherirse a esta iniciativa, enviado en su búsqueda al buque escuela Baquedano; para Gajardo lo que había que hacer era apertrechar esa nave chilena con carbón, viveres y acondicionarla con nuevas instalaciones para ayudarla a soportar los rudos mares y climas antárticos.

Gajardo, en este mismo artículo, señalaba -y casi a nivel de afirmación definitiva- que muchos de los oficiales de la Armada de Chile y los pilotos segundos no dudarían en ofrecerse voluntariamente para integrar la tripulación de aquella iniciativa de rescate en la Antártica; una especie de anhelo contenido de poder navegar por esos mares del continente Antártico.

Acerca de las innovaciones o mejoras que habría que introducir a la corbeta Baquedano, Gajardo expresaba que sería necesario colocarle cañerías de vapor en todas las habitaciones y cámaras, trabajos que serían fácilmente realizables en el dique de Talcahuano. Para dejarlo aún más acondicionado sería menester desmontarle sus cañones de grueso calibre, aprovechando sus santa bárbaras como pañoles de víveres o ropas y dejándole solamente uno o dos cañones de tiro rápido de pequeño calibre para señales. El equipaje sería también necesario reducirlo al míminum de brazos posibles para dejar a bordo sólo los estrictamente necesarios ${ }^{48}$.

47 Nordenskjöld, O. (1906). Viaje al Polo Sur 1904-1905. Barcelona: Ed. Maucci; Anguita, B. (1904). La expedición de la Uruguay. Revista Chilena de Historia Natural, VIII, pp. 127-129; Nordenskjöld y sus compañeros. (1903).
Los beneficios que de esta operación de rescate a la Antártica se obtendrían para la Armada y el país eran muchísimas; en principio una provechosa experiencia para la superioridad naval y un importantísimo ejercicio de instrucción para los guardiamarinas que los pondría a prueba de las cuatro grandes cualidades del hombre de mar: sangre fría, paciencia, perseverancia y tenacidad ${ }^{49}$. A Chile, sin lugar a dudas, le permitiría dejar establecido a nivel mundial que tratándose de auxilios en la mar siempre prevalecería su voluntad humanitaria de asistir en la búsqueda de los náufragos, en este caso el de los suecos en la Antártica.

Como si ello fuera poco, el teniente Gajardo, también afirmaba que una cosa eran la voluntad y los deseos de la institución naval y del propio gobierno chileno, pero otras eran las condiciones profesionales de los tripulantes chilenos, los cuales en Magallanes y en los mares próximos a las islas Diego Ramírez, eran los más aptos y resistentes para una empresa de tal envergadura: demostrando un absoluto desprecio por todos los peligros y llenos de recursos para proporcionarse alimentos sin demostrar jamás aburrimiento, siendo difícil considerar que pueda existir una raza de hombres en el mundo de mayor energía física y más fuertes en las luchas con los elementos [...] He visto a nuestros marinos soportar tranquilamente temperaturas de $20^{\circ}$ bajo cero con la misma ropa que usan en la estación de invierno en el norte, es decir, llevando solamente sobre el cuerpo camiseta, jersey y chompa ${ }^{50}$

De la generación de oficiales de la Armada de Chile a la que perteneció Ismael Gajardo, él es uno de los pocos -sino el único- que se interesó por el tema antártico o polar. Sabemos que dos años después del rescate de Nordenskjold, en 1905, publicó en la Revista de Marina otro artículo llamado Por los Mares Australes: Resumen de las Más Importantes Expediciones Polares Antárticas donde analizó las contribuciones de las

Revista Chilena de Historia Natural, VII, pp. 334-335.

48 Gajardo 1903, op. cit. p. 704 y 706

49 Gajardo 1903, op. cit. p. 706.

50 Gajardo 1903, op. cit. pp. 705-706. 
principales expediciones científicas, especialmente, las de Cook, Weddell, Biscoe, Smith, Bransfield, Palmer, D'Urville, Wilkes, Borchgrevink, Scott, Drygalski, Nordenskjöld, Bruce y Charcot $^{51}$. Sin que podamos afirmar a ciencia cierta de dónde Gajardo logró acopiar tan valiosas informaciones sobre los descubrimientos e intentos de exploración por llegar a conocer el continente antártico, estimamos que estas habrian provenido de los constantes contactos que en diferentes momentos tuvo con Federico Puga Borne, Francisco Fonck y Federico Albert, de la Sociedad Científica de Chile; Luis Riso Patrón y Alejandro Bertrand de la Oficina de Límites; Manuel Señoret, Luis A. Goñi, Federico Chaigneau y Luis Pomar de la OHA y; por último, del mismo Nordenskjöld, todos los cuales habían mostrado su interés por el conocimiento de la Antártica.

La falta de informaciones existentes a mediados de 1903 acerca del paradero del explorador Nordenskjold condujo a que el gobierno argentino organizara una comisión de rescate en la corbeta Uruguay al mando del capitán Julián Irizar. ${ }^{52}$

Hasta la fecha no se tiene conocimiento exacto del momento y lugar en que el Presidente Germán Riesco a insinuación del Director de la Armada Jorge Montt le solicitó a su igual argentino, el Presidente Julio A. Roca, que permitiera integrar en la dotación de la corbeta Uruguay a un oficial naval chileno ${ }^{53}$. Lo que sí sabe es que la favorable respuesta llegó al poco tiempo después a través de una invitación de La Casa Rosada a La Moneda, y el alto mando naval y gobierno chileno designó para este cometido al teniente Alberto Chandler Bannen ${ }^{54}$. En esa fecha Chandler se encontraba sirviendo en Iquique las

51 Gajardo, I. (1905c). Por los mares australes: Resumen de las más importantes expediciones polares antárticas. Revista de Marina, 229, pp. 31-39.

52 "Al Polo Sur". (1903, 1 noviembre). La Unión de Valparaíso, p. 3; "Nueva expedición de rescate". (1903, 5 noviembre). La Unión de Valparaíso, p. 4; "A Punta Arenas pasará expedición de rescate sueca". (1903, 25 noviembre). La Unión de Valparaíso, p. 3; "El "Fridjolf"”. (1903, 24 diciembre). La Unión de Valparaíso, p. 3.

53 "Oficial chileno a la Antártica". (1903, 2 agosto). La Unión de Valparaíso, p. 3

54 Matte, R. (1903). Expedición al polo sur. Revista de funciones de oficial en la nave Ministro Zenteno y que en 1902, como tripulante de la escampavía Cóndor había acompañado al coronel británico Sir Thomas Holdich y al geógrafo chileno Luis Riso Patrón en las observaciones en terreno de los sectores patagónicos que se encontraban en litigio con Argentina ${ }^{55}$ con motivo del proceso del laudo arbitral patagónico de ese mismo año de 1902.

El teniente Chandler antes de partir recibió del director de la OHA Luis Pomar, por memorándum del 16 de septiembre de 1903, un importante número de instrucciones sobre observaciones científicas, náuticas e industriales y otras tareas que debía cumplir mientras durase su comisión a bordo de la corbeta Uruguay. Entre todas ellas, destacaban las de carácter hidrográficas: tomar nota de los sondajes que haga el buque, situando las sondas en una carta o anotándolas en un rejistro [sic] especial, con sus coordenadas y demás datos pertinentes [...] igualmente anotar todos los descubrimientos hidrográficos de importancia que efectúe el buque en los mares australes, tales como islas o canales nuevos, rectificaciones y peligros, etc., [...] si en el curso de la esploración [sic] se hiciere algún levantamiento de plano [...] pedirá permiso al comandante del buque para sacar copia de él, a fin de agregarlo a los documentos que deberá presentar a la Dirección Jeneral [sic] de la Armada ${ }^{56}$.

En cosmografía, le recomendaba que: sacará copia de las observaciones que hagan los oficiales del buque sobre las corrientes oceánicas, su dirección e intensidad, hielos flotantes y la latitud en que se encuentran, temperatura y salinidad del agua, etc. ${ }^{57}$.

En meteorología, se le instruía que como: tendrá un vasto campo para hacer apuntes de

Marina, 205, p. 319; Braun, A. (1974). Pequeña historia antártica. Buenos Aires - Santiago: Ed. Francisco de Aguirre, p. 146; Ministerio de Marina. (1904). Memoria del Ministerio de Marina. Santiago: Talleres Tipográficos de la Armada, p. 393.

55 Abascal, M. (1941). Don Luis Risopatrón. Revista Chilena de Historia y Geografía, 99, p. 9; Valdés, S. (1912). Comisiones desempeñadas desde agosto de 1902 hasta marzo de 1904 por el crucero Presidente Pinto. Anuario Hidrográfico de la Marina de Chile, XXVII, pp. 30-32.

56 Pomar, L. (1903). La expedición argentina al polo sur. Revista de Marina, 207, p. 437.

57 Pomar 1903, op. cit. p. 437. 
gran importancia, que por ser mui [sic] conocidos no necesitan indicarse con más detalles [...] lo mismo puede decirse del magnetismo terrestre [...] sin embargo, puede recomendarse una atención especial a los fenómenos peculiares a esos parajes, como ser las nieblas, las variaciones del viento, los signos que anuncien las tempestades, la proximidad de los hielos en tiempos cerrados, los fenómenos eléctricos, magnéticos y de óptica atmosférica ${ }^{58}$.

En relación a uno de los temas que más interés despertaba en el Ministerio de Industria y Obras Públicas, se le aconsejaba a Chandler observar: la caza y pesca de animales marinos, anfibios y cetáceos, que serán tema de anotaciones del mayor interés para esas industrias marinas. Se hará una lista de las especies de focas y de ballenas, indicando la zona donde se encuentran, su abundancia, tamaño y su utilidad como industria, etc. ${ }^{59}$.

Deseándole a Chandler un provechoso y auspicioso viaje hacia el Polo Sur, el director Pomar le conminaba que a su regreso elaborará una memoria descriptiva con todas las observaciones realizadas en las áreas antes mencionadas; además, y de ser posible, agregar una reseña histórica con los viajes anteriores a la Antártica para comparar los resultados alcanzados por las diversas expediciones desde la primera de Cook, a fines del siglo XVIII, hasta las numerosas exploraciones efectuadas con posterioridad por los buques Bélgica, Southern Cross, Discovery, Gauss y Valdivia y que en lo posible pudiera acompañarlos con una amplia gama de ilustraciones, planos, mapas, vistas panorámicas y dibujos de objetos notables. ${ }^{60}$

Hasta la fecha no nos ha sido posible hallar la memoria que el director Luis Pomar le solicitó a Alberto Chandler a su regreso de la comisión en la corbeta Uruguay, esto a pesar de los numerosos esfuerzos realizados para disponer de esa valiosa pieza histórica. Nuestra impresión es que luego de ser presentada conforme lo exigía la comisión, es decir, a su regreso a Chile en diciembre de 1903,

58 Pomar 1903, op. cit. p. 437.

59 Pomar 1903, op. cit. p. 437.

60 Pomar 1903, op. cit. p. 437.

61 Sociedad Científica de Chile (1905) Sesión General en 19 de junio de 1905. Actes de la Société Scientifique du Chili XV, p.XXIX; Ministerio de Marina 1904, op.cit. p. 384 . ésta pudo quedar en un destino todavía desconocido por nosotros y que esperamos algún día esclarecer.

Cuando había pasado un año del histórico viaje de Alberto Chandler a la Antártica -primer oficial naval chileno en ir en comisión oficial a esa región del mundo-, el capitán Roberto Maldonado, en su calidad de Subdirector de la OHA fue designado para asistir como delegado nacional al VIII Congreso Internacional de Geografía que se celebró en Washington. ${ }^{61}$ En esa ocasión, la comunidad científica internacional acordó adoptar y aplicar variadas resoluciones, algunas de las cuales afectaron el quehacer de la OHA, destacándose: el aumento de los estudios cartográficos y náuticos; la fijación de normas para las escalas de las cartas; la fijación de reglas para la asignación de nombres geográficos; la necesidad de elaborar cartas de profundidades oceánicas y nomenclaturas de composición del fondo; potenciar los estudios geográficos con la implementación de la fotografía; aumentar las observaciones de los témpanos; apoyar a las exploraciones polares y; comenzar a crear institutos dedicados a las observaciones sísmicas. ${ }^{62}$

Los acuerdos adoptados en Washington en 1904 fueron ampliamente conocidos y decisivos en el posterior desarrollo del quehacer institucional y científico chileno. En lo tocante a la fundación de instituciones llamadas al estudio de los fenómenos telúricos y sísmicos, el terremoto de Valparaíso de agosto de 1906, apresuró el llamado de la reunión de Washington y dos años después se fundaba el Instituto Sismológico Nacional a cargo del naturalista francés Montessus de Ballore. ${ }^{63}$ También, años después, en 1916, el gobierno y Armada de Chile auxiliaron a los compañeros náufragos de Shackleton que habían quedado en la isla Elefante, y fueron rescatados por la escampavía Yelcho a cargo del experimentado piloto Luis Pardo Villalón.

Cuando en 1904 Alejandro Bertrand dejó la dirección de la Oficina de Límites dependiente del Ministerio de Relaciones Exteriores, asumió el

62 Oficina Hidrográfica de la Marina de Chile. (1907). Anuario Hidrográfico de la Marina de Chile, XXVI, pp. 44-45.

63 Mancilla, P. (2013). Fernando Montessus de Ballore y Luis Risopatrón: Aportes a la divulgación del conocimiento antártico en Chile, 1906-1916. Estudios Hemisféricos y Polares, 4 (4), pp. 313-322. 
ingeniero geógrafo, Luis Riso Patrón, titulado en la Universidad de Chile y funcionario de esa oficina hace varios años; Riso Patrón era discípulo de Bertrand y estaba llamado a ser el sucesor natural de éste en la Oficina de Límites. Hacia esa fecha había realizado numerosos trabajos científicos y asesorías técnicas destinadas a despejar de forma definitiva las disputas limítrofes con Argentina. En mérito a sus trabajos científicos es que puede ser considerado el principal precursor y difusor del conocimiento antártico chileno a comienzos del siglo XX. ${ }^{64}$

Desde la dirección de la Oficina de Límites ${ }^{65}$, Riso Patrón se dio a la tarea de reunir, coordinar y aprovechar para la ciencia nacional los estudios realizados por las comisiones de límites por más de diez años, publicando consecuentemente dos obras: La Colección de Mapas de la Región Andina, que incorporó los datos obtenidos de los estudios limítrofes con las repúblicas vecinas y los seis volúmenes descriptivos dedicados a la Cordillera de Los Andes ${ }^{66}$, siendo todos estos una contribución al conocimiento y progreso orográfico nacional que, hasta esa fecha, se encontraba atrasadísimo. ${ }^{67}$

Aparte de las personas ya nombradas y que habían tenido una importante participación en el desarrollo de la ciencia y en las investigaciones geográficas sobre la subantártica y Antártica, no podemos dejar de mencionar al general del Ejército de Chile, Jorge Boonen Rivera. ${ }^{68}$ Este destacado militar de comienzos del siglo XX fue el primero en manifestar en la institución castrense la preocupación por la situación geopolítica, administrativa, económica y científica de los

64 Abascal 1941, op. cit. pp. 6-9; Don Luis Risopatrón, geógrafo eminente y benemérito, servidor público. (1941). Revista de Marina, 501, p. 187; Sociedad Chilena de Historia y Geografía. (1918). Sesión General Celebrada por la Sociedad Chilena de Historia y Geografía, el 28 de abril de 1918, con el objeto de hacer entrega al Sr. Luis Risopatrón de la Medalla Anual de Oro correspondiente a 1915. Revista Chilena de Historia y Geografía, 30, pp. 5-29.

65 Abascal 1941, op. cit. pp. 35-37; Donoso, R. (1959). Don Ernesto Greve Schlegel. Revista Chilena de Historia y Geografía, 127, p. 8.

66 Donoso, Á. (1903). La Cordillera de Los Andes entre las latitudes $30^{\circ} 14^{\prime}$ y $35^{\circ}$ Sur. Trabajos y estudios de la Segunda Sub-Comisión Chilena de Limites con la República de Argentina. Santiago: Imprenta Cervantes. sectores más apartados del país, tal cual lo habían declarado en décadas pasadas Bernardo O'Higgins y Manuel Bulnes, respectivamente.

Boonen, quien había escrito Ensayo sobre la Geografía Militar de Chile, publicado en dos volúmenes, el primero en 1897 y el segundo en 1905, logró englobar los principales fundamentos y descripciones de la geografía del país, desde Tarapacá hasta la isla San Ildefonso, basándose en las investigaciones y publicaciones de Diego Barros Arana, Alejandro Bertrand, Luis Riso Patrón, Federico Chaigneau, Francisco Vidal Gormaz, Manuel Señoret, Hans Steffen, Crecente Errázuriz, Nicolás Anrique, Francisco Fonck, entre otros. En los principales capítulos Boonen aportaba someros datos referidos: al clima, los vientos y las posibilidades pesqueras de las zonas subantárticas y antárticas. Finalizando con una especie de llamado patriótico a la Armada de Chile para defender Punta Arenas, estimado por él como la frontera austral que une a Chile con Europa. ${ }^{69}$

Entre las distintas actividades que realizó Boonen, se debe destacar el viaje que efectuó a Punta Arenas a principios de 1905, oportunidad en que aprovechó para entrevistarse e intercambiar opiniones con el Gobernador de Magallanes, Froilán González, sobre la importancia estratégica de las islas ubicadas al sur de Tierra del Fuego. A su regreso, envió un informe al Presidente Germán Riesco, señalando sus impresiones, y especialmente, en lo referente a prestar más atención a las islas Shetland del Sur y la península antártica, con el fin de adelantarse a posibles futuros conflictos relativos al dominio de esas áreas

67 Abascal 1941, op. cit. pp. 17-18; Fuenzalida, H. \& Flores, E. (1956). Estado de la geografía en Chile. Revista Geográfica Militar Terra Australis, 14, p. 100.

68 El General de División don Jorge Boonen Rivera. (1922). Memorial del Ejército de Chile, XVII, pp. 1-4; San Francisco, A. (ed.). (2006). La Academia de Guerra del Ejército de Chile, 1886-2006. Santiago: Centro de Estudios Bicentenarios, p. 221.

69 Boonen, J. (1897). Ensayo sobre la Geografía Militar de Chile. Tomo I. Santiago: Imprenta Cervantes; Boonen, J. (1905). Ensayo sobre la Geografía Militar de Chile. Tomo II. Santiago: Imprenta Cervantes.

70 Garrido, M. (2001). Las pretensiones antárticas chilenas: Aporte histórico de Don Federico Puga Borne. Concepción: Universidad de Concepción, p. 63. 
y que la ocupación debería ser una de las misiones fundamentales del Gobierno. ${ }^{70}$

Pero el interés e ímpetu del general Boonen por emprender la ocupación de estas áreas en la Antártica no cesó. Es así, que en septiembre de 1905, envió un segundo informe al Presidente Riesco, donde enfatizaba la importancia de ocupar los archipiélagos Shetland del Sur y Georgias del Sur. Estos informes remitidos por Boonen habrían sido vitales al momento que el Canciller Federico Puga Borne $e^{71}$ tramitó en 'reserva' la concesión de una licencia que se otorgó en febrero de 1906 a Domingo Toro Herrera y Enrique Fabry. ${ }^{72}$ Esta tercera concesión y al igual que las dos anteriores, abarcaba mares y tierras situadas al sur del Cabo de Hornos 'indefinidamente'.

Otros antecedentes considerados por el Canciller, fueron los informes emanados de los estudios técnicos ejecutados por Guillermo Fritis Mac Kenney, Jefe de la Oficina Topográfica del Ministerio de Tierras y Colonización, que en enero de 1906, señalaba que: el Estado se beneficiaría grandemente accediendo a lo pedido -el otorgamiento de la concesión- por cuanto esas tierras encierran grandes riquezas en minerales que pueden despertar la codicia de alguna nación extranjera $y$, porque en el estado en el que hoy se encuentran no producen ninguna utilidad a la nación, pero una vez que se reconozcan y exploten serán fuente de riqueza para el país ${ }^{73}$.

Los planteamientos antes anotados y que habían sido parte de la decisión para el otorgamiento de la tercera concesión por parte del gobierno chileno también lograban su confirmación con las apreciaciones de Ramón Briones y Humberto Molina, ambos de la Sección de Defensa del Ministerio de Relaciones Exteriores, que expresaban que: no hay inconveniente para conceder a los señores Fabry y Toro Herrera la

71 Jara, M. (1998-1999). Una disputa doblemente pospuesta: Chile y el territorio antártico, 1906-1948. Revista Notas Históricas y Geográficas, 9-10, pp. 131-137; Don Federico Puga Borne. (1907). Revista Zig-Zag, 123.

72 Berguño 1998, op. cit. pp. 4, 11 y 18.

73 Pinochet de la Barra, O. (1977). La antártica chilena y sus implicancias diplomáticas. En: Sánchez, W. (1977). Cientocincuenta Años de política exterior chilena. Santiago: Ed. Universitaria, p. 249; Ministerio de Relaciones Exteriores de Chile. Archivo de Federico Puga Borne. Carpeta 8.1 Temas Australes. Copia de informe tenencia de las islas de la Tierra del Fuego en vista de que se beneficiarian grandemente esas regiones con la explotación de las industrias que ofrecen establecer ${ }^{74}$.

Es así, que los informes y estudios técnicos, elevados al gobierno por Boonen, Fritis, Briones y Molina, y que fueron tomados en cuenta por Puga Borne para el otorgamiento de la concesión anteriormente nombrada, evidenciaban un claro aumento en el interés del gobierno chileno por avanzar y profundizar en los conocimientos de las regiones australes de Chile; el interés por resguardar los recursos chilenos en esa zonas y; la adopción de defensa ante las pretensiones de potencias extranjeras por el valor económico que tenían esas áreas para el desarrollo del país, las cuales no se podrían determinar sin antes realizar las necesarias investigaciones de carácter científico.

Poco antes de la firma del decreto que otorgó la concesión a Domingo Toro Herrera y Enrique Fabry, el Canciller Puga Borne ordenó al general Boonen Rivera contactarse con el Jefe del Destacamento Naval, Arturo Wilson, para que hiciera un estudio de factibilidad y poder enviar un buque a las islas antárticas. En marzo de 1906 y una vez que Boonen había realizado el contacto y consulta con el capitán Wilson, dirigió un acotado e importante informe al Canciller Puga y donde le expresaba que: en cumplimiento a las órdenes que US. se sirvió darme, he impuesto al señor Jefe del Destacamento Naval, de la comisión que el Supremo Gobierno desea confiar a alguna nave del Estado para hacer un acto de presencia en las islas Orcadas y Shetland australes [...] US. con mejor conocimiento determinará si ha llegado el momento de que hagamos siquiera acto de presencia en regiones próximas a nuestras aguas territoriales que se anuncian como emporio de grandes riquezas en materia de pesquería ${ }^{75}$.

emitido por el Jefe de la Sección Topográfica don G. Fritis Mac Kenney.

74 Ministerio de Relaciones Exteriores de Chile. Archivo Federico Puga Borne. Carpeta 8.1: Temas Australes. Copia de informe emitido por la Sección de Defensa, firmado por los señores Ramón Briones y Humberto Molina.

75 Ministerio de Relaciones Exteriores de Chile. Archivo Federico Puga Borne. Carpeta 8.1: Temas Australes. Copia de carta enviada por el General Jorge Boonen Rivera a don Federico Puga Borne de fecha 30 de marzo de 1906. 
El intento de Puga por ir a la Antártica no pudo realizarse y pocos meses después fue retomado por otro proyecto de expedición del Ministerio de Relaciones Exteriores, que al amparo de una nueva instancia de discusión, pensamiento y apoyo al gobierno en los temas polares y antárticos, denominada Comisión Antártica Chilena, creada por su sucesor, Antonio Huneeus Gana en junio de 1906, éste trató de llevar adelante. El terremoto de agosto de 1906 echó por tierra la posibilidad de organizar esta expedición a la Antártica y los recursos que se habían asignado por el Congreso Nacional para ese propósito fueron reasignados para la reconstrucción de Valparaíso, principal ciudad afectada por ese fenómeno de la naturaleza.

\section{A MODO DE CONCLUSIONES}

1. Con posterioridad a la Guerra del Pacífico, la Armada de Chile retomó la prioridad por el territorio de Magallanes y Tierra del Fuego profundizando el conocimiento general que se tenía sobre esas zonas australes chilenas y además seguir con la tarea de instalar estaciones y otros equipamientos para la navegación en el Estrecho de Magallanes y para ir en ayuda de eventuales naufragios y con ello cumplir con asistencia y auxilios humanitarios. 2. El conocimiento e interés por las islas australes se produce a propósito del descubrimiento de lavaderos auríferos y por la amenaza de que esos territorios fueran ocupados por familias provenientes de otras partes del mundo, principalmente argentinos. Frente a esta amenaza, el gobernador de Magallanes, Manuel Señoret, reacciona diseñando un plan de poblamiento y explotación de recursos económicos el cual se inició con el poblamiento de Puerto Toro en la costa oriental de Navarino en 1892.76

3. Los antecedentes científicos, institucionales, históricos y políticos generados entre 18961906, permiten sostener que fue durante esos años cuando se sientan las bases de la Política Antártica Chilena.

4. El gobierno chileno frente a la presión y llegada de expediciones a los mares y tierras antár-

76 Martinic, M. (1973). Panorama de la colonización en Tierra del Fuego entre 1881-1900. Anales del Instituto de la Patagonia, 4. ticas, reaccionó estimulando y dinamizando el quehacer científico nacional, y procurando resguardar los recursos marinos y la jurisdicción de los territorios australes.

5. Consecuencia de lo anterior es que miembros de la Armada de Chile participaron en reuniones en Londres en 1895 -Luis A. Goñi- y luego en Francia en 1896 con motivo de un Congreso Científico ${ }^{77}$-Luis Uribe Orrego y Lindor Pérez Gacitúa- y ofrecieron apoyo a las expediciones que se organizaran para la Antártica a objeto de ganar experiencias y reconocimiento internacional.

6. El año 1906 es una fecha culminante en el proceso de acercamiento de Chile por la Antártica, ya sea porque se otorgan otras concesiones para 'mares y tierras' al sur del Cabo de Hornos y por ser el año del primer intento chileno para organizar una expedición a las islas Shetland del Sur y la península Antártica por parte de la recién creada Comisión Antártica Chilena.

\section{AGRADECIMIENTOS}

Proyecto FONDECYT No 1120080 Política Antártica Chilena, 1902-1908: ¿Reconocimiento Internacional o Postergación Polar? Universidad de Playa Ancha, Facultad de Humanidades, Departamento de Historia, Valparaíso, Chile.

\section{FUENTES DE CONSULTA}

a) Impresas

Abascal, M. (1941). Don Luis Risopatrón. Revista Chilena de Historia y Geografía XCI (99), 5-98.

Albert, F. (1901a). Los lobos marinos de Chile. Revista Chilena de Historia Natural V, 41

Albert, F. (1901b). Los pinípedos de Chile. Actes de la Société Scientifique du Chili XI, 219-257.

Anguita, B. (1904). La expedición de la Uruguay. Revista Chilena de Historia Natural VIII, 127-129.

Barrera, H. (1983). Los asuntos antárticos y la participación de algunas instituciones chilenas. Boletín Antártico Chileno III (2), 16-26.

Beauvor, J. M. (1915). Los Shelknam: Indígenas de Tierra del Fuego. Buenos Aires: Talleres Litográficos de la Compañía de Fósforos.

Becerra, R. (1895). Reglamento para llevar los diarios de bitácora. Revista de Marina XIX (113), 545-551.

77 Congreso Científico Internacional. (1896). Anales de la Universidad de Chile, XCV, pp. 118-119. 
Berguño, J. (1997). La exploración de los mares australes por navíos españoles durante el siglo XVIII. Boletín Antártico Chileno 16(2), 2-10.

Berguño, J. (1998). El despertar de la conciencia antártica (1874-1914): Origen y desarrollo de la cooperación científica internacional. Boletín Antártico Chileno 17(2), 2-13.

Berguño, J. y Canales, R. (2005). La Antártica en Punta Arenas, ayer y hoy. Boletín Antártico Chileno 24(2), 20-23.

Boonen, J. (1897). Ensayo sobre la Geografía Militar de Chile. Tomo I. Santiago: Imprenta Cervantes.

Boonen, J. (1905). Ensayo sobre la Geografía Militar de Chile. Tomo II. Santiago: Imprenta Cervantes.

Braun, A. (1974). Pequeña historia antártica. Buenos Aires - Santiago: Editorial Francisco de Aguirre.

Chaigneau, F. (1898). La pesca ante el porvenir de la Marina de Guerra. Revista de Marina XXV(150), 2.1942.196.

Delfín, F. (1903). Carábidos nuevos chilenos descubiertos por la expedición antártica belga. Revista Chilena de Historia Natural VII, 229.

Destefani, L. (1982). Malvinas, Georgias y Sándwich del Sur ante el Conflicto con Gran Bretaña. Buenos Aires: Editorial Edipress.

Donoso, Á. (1903). La Cordillera de Los Andes entre las latitudes $30^{\circ} 14^{\prime}$ y $35^{\circ}$ Sur. Trabajos y estudios de la Segunda Sub-Comisión Chilena de Límites con la República de Argentina. Santiago: Imprenta Cervantes.

Donoso, Á. (1906). Demarcación de la línea de frontera en la parte sur del territorio: Trabajos de la Quinta Sub-Comisión Chilena de Limites con la República de Argentina. Santiago: Imprenta Cervantes.

Donoso, R. (1959). Don Ernesto Greve Schlegel. Revista Chilena de Historia y Geografía 127, 5-66.

Escudero, J. (1953). Cincuentenario de la política antártica chilena. Boletín de la Academia Chilena de la Historia XX (48), 73-78.

Fonck, F. (1893). Introducción a la Orografía y Geología de la región austral de Sud-América. Valparaíso: Editorial Carlos F. Niemeyer.

Fonck, F. (1896). Bibliografía Marítima Chilena. Revista de Marina 121, 130-131.

Fuenzalida, H. y Flores, E. (1956). Estado de la geografía en Chile. Revista Geográfica Militar Terra Australis 14, 97-111.

Gajardo, I. (1903). Un socorro oportuno a los expedicionarios del Antarctic. Revista de Marina XXXIV (204), 703708.

Gajardo, I. (1905a). Por los mares australes: Reminiscencias de la primera campaña del Antarctic a las Tierras del Rey Óscar II. Revista de Marina XXXVIII (227), 640649.

Gajardo, I. (1905b). Viaje de la escampavía Huemul a las islas australes de la Tierra del Fuego en marzo de 1902. Anuario Hidrográfico de la Marina de Chile XXV, 25-46.

Gajardo, I. (1905c). Por los mares australes: Resumen de las más importantes expediciones polares antárticas. Revista de Marina XXXIX(229), 31-39.

Garrido, M. (2001). Las pretensiones antárticas chilenas:
Aporte histórico de Don Federico Puga Borne. Concepción: Universidad de Concepción.

Jara, M. (1998-1999). Una disputa doblemente pospuesta: Chile y el territorio antártico, 1906-1948. Revista Notas Históricas y Geográficas 9-10, 24-31.

Jara, M. (2012). Las 'Islas Australes' y los prolegómenos de la política antártica chilena, 1892-1896. Estudios Hemisféricos y Polares, 3(4), 269-286.

Jara, M. (2013). Gerlache's Belgique in the social imaginary of Punta Arenas, 1897-1899. Estudios Hemisféricos y Polares 4(3), 200-210.

Kirwan, L. P. (2001). Historia de las exploraciones polares. Barcelona: Luis de Caralt Editor.

Macaya, J. y Fonck. A. (2005). Francisco Adolfo Fonck Foveaux (1830-1912) y su importancia en la botánica chilena del siglo XIX-XX. Revista Chilena de Flora y Vegetación 8(2), 1-7

Mancilla, P. (2013). Fernando Montessus de Ballore y Luis Risopatrón: Aportes a la divulgación del conocimiento antártico en Chile, 1906-1916. Estudios Hemisféricos y Polares 4(4), 313-322.

Martinic, M. (1972). Nuevos antecedentes sobre actividades nacionales en el territorio antártico durante las primeras décadas del siglo XX. Anales del Instituto de la Patagonia III(1-2), 31-47.

Martinic, M. (1973). Panorama de la colonización en Tierra del Fuego entre 1881-1900. Anales del Instituto de la Patagonia, 4.

Martinic, M. (2002). Marinos a caballo. Exploraciones terrestres de la Armada de Chile en la Patagonia Austral y la Tierra del Fuego, 1877-1897. Valparaíso: Editorial Puntángeles.

Matte, R. (1903). Expedición al polo sur. Revista de Marina XXXV (206), 319.

Ministerio de Marina. (1896). Memoria del Ministerio de Marina. Santiago: Talleres Tipográficos de la Armada.

Ministerio de Marina. (1903). Memoria del Ministerio de Marina. Santiago: Talleres Tipográficos de la Armada.

Ministerio de Marina. (1904). Memoria del Ministerio de Marina. Santiago: Talleres Tipográficos de la Armada.

Mouchez, E. A. B. (1897). Hidrografía y levantamientos rápidos durante los viajes. Revista de Marina XXIII(133), 17-34.

Nogues, A. (1891). Quelques remarques sismiques, à propos de la communication de M. Obrecht. Actes de la Société Scientifique du Chili I, 115-119.

Nordenskjöld, O. (1897). Algunos datos sobre la parte austral del continente sudamericano según estudios hechos por la comisión científica Suecia. Actes de la Société Scientifique du Chili VII, 157-168

Nordenskjöld, O. (1906). Viaje al Polo Sur 1904-1905. Barcelona: Editorial Maucci.

Obrecht, A. (1891). Sur Les Mouvements du Sol à Santiago. Actes de la Société Scientifique du Chili I, 108-114.

Oficina Hidrográfica de la Marina de Chile. (1896). Anuario Hidrográfico de la Marina de Chile XIX, 5-13.

Oficina Hidrográfica de la Marina de Chile. (1901). Anuario Hidrográfico de la Marina de Chile, 5-17.

Oficina Hidrográfica de la Marina de Chile. (1903). Anuario Hidrográfico de la Marina de Chile XXIV, 5-30.

Oficina Hidrográfica de la Marina de Chile. (1907). Anuario Hidrográfico de la Marina de Chile XXVI, 5-55.

Pacheco, B. (1930). Derrotero del archipiélago de la Tierra 
del Fuego. Anuario Hidrográfico de la Marina de Chile XXXV, 1-210.

Paravic, S. (1988). Chile y el desafío antártico internacional. Memorial del Ejército de Chile 428, 95-121.

Pinochet de la Barra, O. (1977). La antártica chilena y sus implicancias diplomáticas. En Sánchez, W. (Ed.), Cientocincuenta Años de política exterior chilena. Santiago: Editorial Universitaria.

Pomar, L. (1903). La expedición argentina al polo sur. Revista de Marina XXXV(207), 436-438.

Porter, C. (1900). Los musgos colectados por la expedición antártica belga en el Estrecho de Magallanes y Tierra del Fuego. Revista Chilena de Historia Natural IV, 102-106.

Porter, C. (1903). Dípteros nuevos chilenos descubiertos por la expedición antártica belga. Revista Chilena de Historia Natural VII, 218-220.

Romero, H. (1962). La universidad y la investigación científica. Anales de la Universidad de Chile 125, 15-29.

Romero, P. (1985). Presencia de Chile en la Antártica. Memorial del Ejército de Chile 49, 110-114.

San Francisco, A. (Ed.). (2006). La Academia de Guerra del Ejército de Chile, 1886-2006. Santiago: Centro de Estudios Bicentenarios.

Sociedad Chilena de Historia y Geografía. (1918). Sesión General Celebrada por la Sociedad Chilena de Historia y Geografía, el 28 de abril de 1918, con el objeto de hacer entrega al Sr. Luis Risopatrón de la Medalla Anual de Oro correspondiente a 1915. Revista Chilena de Historia y Geografía VIII(30), 5-29.

Sociedad Científica de Chile. (1891). Reglement. Actes de la Société Scientifique du Chili I, 7.

Sociedad Científica de Chile. (1897). Sesión General en 5 de julio de 1897. Actes de la Société Scientifique du Chili VII, 30

Sociedad Científica de Chile. (1897). Sesión General en 15 de noviembre de 1897. Actes de la Société Scientifique du Chili VII, 37.

Sociedad Científica de Chile. (1905). Sesión General en 19 de junio de 1905. Actes de la Société Scientifique du Chili XV, 29.

Toro, C. (1986). Presencia de Chile en la Antártica. Santiago: Editorial Universitaria.

Valdés, S. (1912). Comisiones desempeñadas desde agosto de 1902 hasta marzo de 1904 por el crucero Presidente Pinto. Anuario Hidrográfico de la Marina de Chile XXVII, 27-48.

Vercel, R. (1942). Al Asalto de los Polos. Santiago: Editorial Difusión.
Congreso Científico Internacional. (1896). Anales de la Universidad de Chile XCV, 118-119.

Nordenskjöld y sus compañeros. (1903). Revista Chilena de Historia Natural VII, 334-335.

Don Federico Puga Borne. (1907). Revista Zig-Zag III(123), $\mathrm{s} / \mathrm{p}$.

El General de División don Jorge Boonen Rivera. (1922). Memorial del Ejército de Chile XVII, 1.

Don Luis Risopatrón, geógrafo eminente y benemérito, servidor público. (1941). Revista de Marina 501 187.

b) Prensa

Las pesquerías de lobos en los mares magallánicos. (1894, 2 septiembre). El Magallanes de Punta Arenas.

Comisión Científica Sueca. (1896, 26 enero). El Magallanes de Punta Arenas.

Carbón de Tierra del Fuego. Informe del Dr. N. Otto G. Nordenskjold sobre su visita a las minas de carbón cerca del río Cóndor, Tierra del Fuego. (1896, 3 mayo). El Magallanes de Punta Arenas.

Las islas Shetland del Sud. Expedición argentina al polo austral - Mapa del archipiélago. (1896, 16 noviembre). La Prensa de Buenos Aires.

Oficial chileno a la Antártica. (1903, 2 agosto). La Unión de Valparaíso.

Al Polo Sur. (1903, 1 noviembre). La Unión de Valparaíso.

Nueva expedición de rescate. (1903, 5 noviembre). La Unión de Valparaíso.

A Punta Arenas pasará expedición de rescate sueca. (1903, 25 noviembre). La Unión de Valparaíso.

El Fridjolf. (1903, 24 diciembre). La Unión de Valparaíso.

c) Archivos Documentales

Ministerio de Relaciones Exteriores de Chile. Archivo de Federico Puga Borne. Carpeta 8.1 "Temas Australes". Copia de informe emitido por el Jefe de la Sección Topográfica don G. Fritis Mac Kenney.

Ministerio de Relaciones Exteriores de Chile. Archivo Federico Puga Borne. Carpeta 8.1: "Temas Australes". Copia de informe emitido por la Sección de Defensa, firmado por los señores Ramón Briones y Humberto Molina.

Ministerio de Relaciones Exteriores de Chile. Archivo Federico Puga Borne. Carpeta 8.1: "Temas Australes". Copia de carta enviada por el General Jorge Boonen Rivera a don Federico Puga Borne de fecha 30 de marzo de 1906. 
M. JARA \& P. MANCILLA 